\title{
A Sports Recreational Program for Decreasing Separation Anxiety Among Children
}

\section{Dr. Ahmed Mohamed Shawkey}

\section{Introduction and Research Problem:}

Childhood is a significant stage in human life. During this stage, the early roots of the child's character are formed as the child acquires the experiences and behaviors that form his/her future attitudes and behaviors later in life. Also, during this stage the child is more vulnerable to several psychological, behavioral, social and school problems and disorders. Therefore, children in this stage require full support and good care to be able to adapt with themselves and their society.

Anxiety disorders among children are various and different in categorization, causes, diagnosis and treatment. They include general anxiety, separation anxiety social anxiety and school rejection. Children with separation anxiety usually avoid situations that may lead to separation from their care givers or safe places. They usually adopt some negative defensive behaviors like rage fits, yelling, begging or even threats to avoid such situations. Such behaviors may be reinforced by parents till they increase and turn into disorder (2: 1-2).

Different types and categories of anxiety disorders are considered as common disorders among children and teenagers. If they are not treated well, they may have negative consequences on the long run (8:263).

Schneider (2011) indicated that anxiety disorder is one of the first disorders that may affect children and causes many problems later as it decreases the academic achievement level and weakens family relations in addition to the clear malfunction of social performance. Furthermore, it is one of the predictors for more disorders in adulthood like panic attacks, depression and addiction (15: 207).

Mostafa, H. (2003) indicated during early life, the child fears separation from his/her mother in addition to unfamiliar places. It is natural that these fears disappear by the third year of life. But if fear and anxiety increase in intensity and continue to later time, it becomes incompatible response and turns into disorder as the child panics in unfamiliar situations and from strangers. His/her attachment to the mother increases making it very difficult to separate him/her from the mother even for a short time (3: 266-267). 
Silveman \& Dick-Niderhauser (2004) indicated that separation anxiety is a common psychological disorder during childhood. It is manifested as chronic unrealistic fear of being separated from a person the child is attached to, mostly parents, and this adversely affects the child's daily activities and normal growth (17: 175).

As a common disorder, separation anxiety may continue to adulthood causing serious other disorders like panic attacks. It is a developmentally unsuitable permanent hyper anxiety towards separation from certain individuals the child is attached to. Its symptoms include severe sadness, avoid being alone and fear of sleeping alone inside or outside the house (11: 17-22).

Separation anxiety is a chronic unrealistic anxiety towards situations of separation from individuals the person is attached to. To may last for at least four weeks causing severe shyness in academic and social tasks (6: 192).

It is a state of chronic sadness and anxiety that affects the child when being separated from home or one family member, especially the mother. It is manifested in severe unsuitable fear of separation and expecting that parents may be harmed or never return after separation (7:33).

Rabia, F. (2012) (13), SHoaakazemi et al (2012) (16), Khadar et al. (2013) (9) and Abd Al-Fattah, S. (2018) (2) indicated that separation anxiety is very common during childhood and may continue to later stages in life causing severe effects and undesired problems for the individuals' psychological formation and future.

Recreational games and activities fulfill the integrated human needs (physical - psychological and emotional - social). It provides individuals with the opportunity to improve their abilities and potentials in addition to strengthening their will and sense of responsibility. It is an educational tool for developing all health, physical, cultural, mental, psychological, emotional, social and ethical aspects of the human character (12: 20-26).

Recreational games and activities protect the individual from anxiety, stress, depression and distress. Through these activities, the individual can express himself, form friendships, cooperate and interact with others and feel happiness, satisfaction, comfort and confidence. It improves quality of life and enhances physical, mental, psychological and social well-being (18: 17-26) (20: 44-46) (14: 1-4, 51, 74, 82, 88, 155, 156).

The researcher noticed that separation anxiety disorder is very common among children with clear symptoms like being unable to stay at school without their parents, weeping fits, being unable to interact with peers, general dislike of school and preferring to return home quickly. This 
may affect their characters, life, academic achievement and future negatively. Therefore, it is necessary to help those children decrease the separation anxiety among them. this led the researcher to try to design a sports recreational program for decreasing separation anxiety among children. According to the researcher's knowledge, no previous research tried to do so.

Aim:

The current research aims to decrease separation anxiety among children through a sports recreational program.

\section{Hypothesis:}

- There are statistically significant differences between the pre- and post-measurements of participants in decreasing separation anxiety in favor of post-measurements through a sports recreational program.

Methods:

Approach:

The researcher used the experimental approach (one-group design) with pre- and post-measurements.

\section{Participants:}

Research community ( $\mathrm{n}=287)$ included all students of Ammar Ibn Yasser Official linguistic School - al-Santa - Gharbia, during 2018-2019 academic year (9-12 years). After applying Separation Anxiety Scale on them, the researcher purposefully chose (36) students who got the highest points on the scale to be the main sample $(12.543 \%$ of research community). Socio-economic conditions of their families were stable. Table (1) shows data normality on all research variables for participants.

Table (1): Data Normality on Growth Factors and Separation Anxiety for Participants ( $n=36)$

\begin{tabular}{|c|c|c|c|c|c|c|c|c|}
\hline $\mathbf{S}$ & \multicolumn{2}{|c|}{ Variables } & \multirow{2}{*}{ Measurement } & \multirow{2}{*}{$\begin{array}{l}\text { Mean } \\
9.9389\end{array}$} & Median & SD & \multicolumn{2}{|c|}{ Kurtosis Squewness } \\
\hline \multirow{3}{*}{$\begin{array}{l}\frac{1}{2} \\
3\end{array}$} & \multirow{3}{*}{ 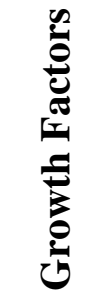 } & Age & & & 9.750 & 0.845 & -0.376 & 0.783 \\
\hline & & Height & $\mathbf{C m}$ & 136.361 & 136.500 & 3.586 & -0.139 & 0.223 \\
\hline & & Weight & $\mathbf{K g}$ & 37.916 & 38.00 & 3.508 & -0.254 & 0.380 \\
\hline \multirow[t]{5}{*}{4} & \multirow{5}{*}{ 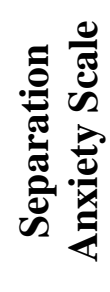 } & Personal & Point & 34.916 & 35.00 & 1.156 & 0.737 & -0.576 \\
\hline & & Social & Point & 22.027 & 22.00 & 1.133 & -0.609 & -0.181 \\
\hline & & Physiological & Point & 24.194 & 24.00 & 1.237 & -0.601 & 0.287 \\
\hline & & Academic & Point & 32.361 & 32.00 & 1.396 & -0.875 & 0.103 \\
\hline & & Total & Point & 1113.500 & 114.00 & 2.813 & $\overline{0.078}$ & -0.685 \\
\hline
\end{tabular}


Table (1) indicated that squewness values were between $( \pm 3)$. This indicates data normality as it is free of radical distributions.

Data Collection Tools:

\section{1-Separation Anxiety Scale for Children (by: Sara Gaber Abd Al-Fattah} 2018) (2)

This scale includes (42) items distributed of (4) dimensions as follows:

- Personal Dimension: This dimension includes all manifestations and personal components of the child who suffers separation anxiety disorder. these are all related to discomfort, continuous anxiety, continuous fear, repeated nightmares, stimulation, fear of being alone, thoughts about separation. The dimension includes (13) items including (1-5-8-11-14-17-20-23-27-30-33-36-40).

- Social Dimension: This dimension measures the effects of separation anxiety on the child and his/her relations with others in addition to his/her social practices in case of separation from the attaché (mother/father). The dimension includes (8) items including (2-6-12-18-24-28-34-37).

- Physiological Dimension: This dimension measures physiological symptoms shown by the child during and after separation (headache - sweat - stomachache - increased heart rate). These symptoms are major indicators for separation anxiety. The dimension includes (9) items including (3-9-15-21-25-31-35-38-41).

- Academic Dimension: This dimension includes the child's fears of school, school rejection, the urge not to leave home, the academic effects not related to academic acquisition but resulting from separation and its negative effects. The dimension includes (12) items including (4-7-10-13-16-19-22-26-29-32-39-42).

Response is based on three-point Likert scale where: Yes $=3-$ somehow $=2-$ no $=1$. For items (2-21-24-27-28-33-35), this scale is reversed. The total score of the scale is between (42) and (126). Higher scores indicate the separation anxiety disorder.

The researcher verified the scale's validity and reliability through the first pilot study initiated from 10-2-2019 to 17-2-2019 on a pilot sample $(n=20)$ from the same research community and outside the main sample. The researcher verified validity using internal consistency calculated with correlations between the item and its dimension and the item and total score as seen in tables (2) and (3). The researcher also verified the scale reliability through calculating correlations between test and retest in addition to Cronbach's Alpha as seen in tables (4) and (5). 
Table (2): Internal Consistency of the Separation Anxiety Scale (n=20)

\begin{tabular}{|c|c|c|c|c|c|c|c|c|c|c|c|}
\hline \multicolumn{12}{|c|}{$\mathbf{R}$} \\
\hline & \multicolumn{2}{|c|}{ First Dimension } & \multicolumn{3}{|c|}{ Second Dimension } & \multicolumn{3}{|c|}{ Third Dimension } & \multicolumn{3}{|c|}{ Fourth Dimension } \\
\hline $\mathbf{S}$ & $\begin{array}{l}\text { Item with } \\
\text { Dimension }\end{array}$ & $\begin{array}{l}\text { Item with } \\
\text { total Score }\end{array}$ & $\mathbf{S}$ & $\begin{array}{l}\text { Item with } \\
\text { Dimension }\end{array}$ & $\begin{array}{l}\text { Item with } \\
\text { total Score }\end{array}$ & $\mathbf{S}$ & $\begin{array}{l}\text { Item with } \\
\text { Dimension }\end{array}$ & $\begin{array}{l}\text { Item with total } \\
\text { Score }\end{array}$ & $\mathbf{S}$ & $\begin{array}{l}\text { Item with } \\
\text { Dimension }\end{array}$ & $\begin{array}{l}\text { Item with } \\
\text { total Score }\end{array}$ \\
\hline 1 & $0.840 * *$ & $0.824 * *$ & 1 & $0.825 * *$ & $0.831 * *$ & 1 & $0.890 * *$ & $0.920 * *$ & 1 & $0.866 * *$ & $0.838 * *$ \\
\hline 2 & $0.902 * *$ & $0.931 * *$ & 2 & $0.874 * *$ & $0.851 * *$ & 2 & $0.844 * *$ & $0.833 * *$ & 2 & 0.938** & $0.869 * *$ \\
\hline 3 & $0.850 * *$ & $0.878 * *$ & 3 & $0.946 * *$ & $0.946 * *$ & 3 & $0.954 * *$ & $0.952 * *$ & 3 & $0.955 * *$ & $0.934 * *$ \\
\hline 4 & $0.904 * *$ & $0.920 * *$ & 4 & $0.828 * *$ & $0.844 * *$ & 4 & $0.858 * *$ & $0.855 * *$ & 4 & $0.912 * *$ & $0.911 * *$ \\
\hline 5 & $0.831 * *$ & $0.833 * *$ & 5 & $0.960 * *$ & $0.952 * *$ & 5 & $0.843 * *$ & $0.814 * *$ & 5 & $0.980 * *$ & $0.943 * *$ \\
\hline 6 & $0.956 * *$ & $0.952 * *$ & 6 & $0.883 * *$ & $0.855 * *$ & 6 & $0.894 * *$ & $0.881 * *$ & 6 & $0.844 * *$ & $0.852 * *$ \\
\hline 7 & $0.879 * *$ & $0.855 * *$ & 7 & $0.835 * *$ & $0.814 * *$ & 7 & $0.828 * *$ & $0.844 * *$ & 7 & $0.854 * *$ & $0.909 * *$ \\
\hline 8 & $0.873 * *$ & $0.876 * *$ & 8 & $0.863 * *$ & $0.874 * *$ & 8 & $0.864 * *$ & $0.808 * *$ & 8 & $0.875 * *$ & $0.803 * *$ \\
\hline 9 & $0.847 * *$ & $0.824 * *$ & & & & 9 & $0.917 * *$ & $0.910 * *$ & 9 & $0.891 * *$ & $0.908 * *$ \\
\hline $\begin{array}{l}\mathbf{1} \\
\mathbf{0}\end{array}$ & $0.946 * *$ & $0.912 * *$ & & & & & & & 10 & $0.934 * *$ & $0.922 * *$ \\
\hline $\begin{array}{l}1 \\
1\end{array}$ & $0.914 * *$ & $0.896 * *$ & & & & & & & 11 & $0.824 * *$ & $0.837 * *$ \\
\hline $\begin{array}{l}1 \\
2\end{array}$ & $0.955 * *$ & $0.946 * *$ & & & & & & & 12 & 0.938** & $0.869 * *$ \\
\hline $\begin{array}{l}1 \\
3\end{array}$ & $0.862 * *$ & $0.844 * *$ & & & & & & & & & \\
\hline
\end{tabular}

Table (2) indicated statistically significant correlations between each item and its dimension ranging from (0.825) to (0.980). in addition, there are statistically significant correlation between each item and total score ranging from (0.803) to (0.952). this indicates the scale's internal consistency. 
Table (3): Internal Consistency between each dimension and total score of the Separation Anxiety Scale $(n=20)$

\begin{tabular}{c|c|c}
\hline \hline$S$ & Dimensions & $\mathbf{R}$ \\
\hline \hline 1 & Personal & $0.993 * *$ \\
\hline 2 & Social & $0.993 * *$ \\
\hline 3 & Physiological & $0.990 * *$ \\
\hline 4 & Academic & $0.979 * *$ \\
\hline \hline \multicolumn{2}{c}{} \\
& $*$ R table value on $P \leq 0.05=0.433$ \\
& $* *$ table value on $P \leq 0.01=0.549$
\end{tabular}

Table (3) indicated statistically significant correlations between each dimension and total score of the Separation Anxiety Scale.

Table (4): Correlations between test and retest for reliability of the Separation Anxiety Scale ( $\mathbf{n = 2 0})$

\begin{tabular}{|c|c|c|c|c|c|c|}
\hline \multirow{2}{*}{$\mathbf{S}$} & \multirow{2}{*}{ Dimensions } & \multicolumn{2}{|c|}{ Test } & \multicolumn{2}{|c|}{ Retest } & \multirow{2}{*}{$\mathbf{R}$} \\
\hline & & Mean & SD士 & Mean & SD士 & \\
\hline 1 & Personal & 25.300 & 9.454 & 26.150 & 9.120 & $0.988 * *$ \\
\hline 2 & Social & 15.550 & 5.605 & 16.350 & 5.640 & $0.971 * *$ \\
\hline 3 & Physiological & 18.100 & 6.273 & 18.750 & 6.536 & $0.985 * *$ \\
\hline 4 & Academic & 23.250 & 8.583 & 24.00 & 8.052 & $0.989 * *$ \\
\hline 5 & Total & 82.200 & 29.571 & 85.250 & 28.683 & $0.998 * *$ \\
\hline
\end{tabular}

$* R$ table value on $P \leq 0.05=0.433$

$* * R$ table value on $P \leq 0.01=0.549$

Table (4) indicated statistically significant correlations between test and retest for Separation Anxiety Scale indicating Reliability of the scale.

Table (5): Cronbach's Alpha for reliability of Separation Anxiety Scale $(\mathbf{n}=\mathbf{2 0})$

\begin{tabular}{c|c|c}
\hline \multicolumn{3}{|c}{ Alpha } \\
\hline \hline \multicolumn{2}{|c}{0.874} & $\begin{array}{c}\text { Cronbach's Alpha if Item } \\
\text { Deleted }\end{array}$ \\
\hline \hline 1 & Dimensions & $\mathbf{0 . 8 5 2}$ \\
\hline 2 & Personal & $\mathbf{0 . 8 5 9}$ \\
\hline 3 & Social & $\mathbf{0 . 8 5 8}$ \\
\hline 4 & Physiological & $\mathbf{0 . 8 5 4}$ \\
\hline \hline
\end{tabular}

Table (5) indicated that all values of Cronbach's Alpha for the scale dimensions are statistically significant, indicating the scale's reliability.

\section{2- The Sports Recreational Program (by the researcher)}

The researcher chose a group of recreational activities and games to increase happiness, joy and comfort, independence, and to decrease separation anxiety among children. Experts of recreation, psychology and mental health $(n=7)$ indicated the importance of these activities as their agreement percentages ranged from $85.72 \%$ to $100 \%$. The activities and games were distributed to the Program units. 
Aim:

The Program aims to decrease separation anxiety children and help them achieve personal happiness.

\section{Principles:}

- Considering all psychological, mental, physical and socio-economic aspects of children (9-12 years).

- Considering progression, variation and individual differences.

- Considering rest intervals.

- Considering safety procedures.

- Considering excitement, joy and enjoyment when applying the activities and games using attractive and colorful tools.

- Encouraging participants continually

- Applying the Program with music and songs.

\section{Content:}

The Program includes three parts:

- Start-up: This part aims to prepare children physically and mentally through joy and enthusiasm to actively participate in the unit to decrease separation anxiety among children. This part includes some recreational games for (10) minutes.

- Main part: This part includes the main games and activities that work on reducing separation anxiety among children according to the unit and Program objectives. It lasts for (40) minutes.

- Conclusion: This part aims to cool-down the body and return it to normal conditions. It includes some recreational games for (10) minutes.

The researcher prepared the preliminary version of the Program and presented it to (7) experts of recreation, psychology and mental health who eliminated a minor number of games.

Activities:

- Soccer

- Volleyball

- Handball

- Basketball

- Recreational games.

Most games depend on team relay format and the team wins when finishing the game first. All games and activities are applied with music and songs. Children are encouraged verbally to participate and are given gifts and prizes. 
The researcher performed the second pilot study from 18-2-2019 to 20-2-2019 to test the suitability of the Program.

The Program includes (32) units and lasts for almost (2) months (4 units per week for 8 weeks) as seen in tables (6) and (7). The researcher applied the Program directly with instructions for participants according to their abilities.

Table (6): Timeframe of the Recreational Games Program

\begin{tabular}{|c|c|}
\hline Total Duration & 2 months \\
\hline Units per week & 4 units \\
\hline Total units & 32 units -8 weeks \\
\hline Unit duration & $60 \mathrm{~min}$ \\
\hline Startup duration & $10 \mathrm{~min}$ \\
\hline Main part duration & $40 \mathrm{~min}$ \\
\hline Conclusion duration & $10 \mathrm{~min}$ \\
\hline Total duration per week & $60 \times 4=240 \mathrm{~min}$ \\
\hline Total duration per month & $240 \times 4=960 \mathrm{~min}$ \\
\hline Total duration in (3) months & $960 \times 2=1920 \mathrm{~min}$ \\
\hline
\end{tabular}

Table (7): Relative Distribution of the Recreational Games Program Units

\begin{tabular}{c|c|c|c|c|c}
\hline \hline Unit parts & $\begin{array}{c}\text { Per day } \\
(\text { min })\end{array}$ & $\begin{array}{c}\text { Per week } \\
(\text { min })\end{array}$ & $\begin{array}{c}\text { Per } \\
\text { month } \\
(\text { min })\end{array}$ & $\begin{array}{c}\text { In 2 months } \\
(\text { min })\end{array}$ & Percentage \\
\hline \hline Start up & 10 & 40 & 160 & 320 & $16.66 \%$ \\
\hline Main part & 40 & 160 & 640 & 1280 & $66.66 \%$ \\
\hline Conclusion & 10 & 40 & 160 & 320 & $16.66 \%$ \\
\hline Total & 60 & 240 & 960 & 1920 & $100 \%$ \\
\hline \hline
\end{tabular}

Main Study:

After verifying the validity and reliability of the scale and the recommended Program, and fulfilling all administrative requirements, the researcher initiated the following:

- Pre-measurement: The researcher applied the Separation Anxiety Scale to the main sample $(n=36)$ on $21-2-2019$ as a premeasurement.

- Main application of the Program: The researcher applied the recreational games Program to the main sample from 24-2-2019 to 18-4-2019. The Program lasted for (2) months (8 weeks with 4 units per week). Total number of units was (32).

- Post-measurement: The researcher applied the Separation Anxiety Scale to the main sample $(n=36)$ on $21-4-2019$ as a postmeasurement. 
Table (8): Timeframe of the Program and measurements

\begin{tabular}{|c|c|c|c|c|}
\hline \multicolumn{2}{|r|}{ Week } & \multicolumn{3}{|c|}{ Days } \\
\hline \multicolumn{3}{|c|}{ First pilot study } & \multicolumn{2}{|c|}{$\begin{array}{l}\text { Sunday 10-2-2019 } \\
\text { Sunday 17-2-2019 }\end{array}$} \\
\hline Sec & ad pilot study & $\begin{array}{l}\text { Monday 18-2- } \\
2019\end{array}$ & $\begin{array}{c}\text { Tuesday 19-2- } \\
2019 \\
\end{array}$ & $\begin{array}{c}\text { Wednesday } 20-2- \\
2019\end{array}$ \\
\hline \multicolumn{3}{|c|}{ Pre-measurement } & \multicolumn{2}{|c|}{$\begin{array}{l}\text { Thursday 21-2-2019 } \\
\end{array}$} \\
\hline \multicolumn{5}{|c|}{ Main application } \\
\hline 1 & $\begin{array}{c}\text { Sunday 24-2- } \\
2019\end{array}$ & $\begin{array}{c}\text { Monday 25-2- } \\
2019\end{array}$ & $\begin{array}{c}\text { Wednesday 27- } \\
2-2019\end{array}$ & $\begin{array}{c}\text { Thursday 28-2- } \\
2019\end{array}$ \\
\hline 2 & 3-3-2019 & 4-3-2019 & 6-3-2019 & 7-3-2019 \\
\hline 3 & 10-3-2019 & 11-3-2019 & 13-3-2019 & 14-3-2019 \\
\hline 4 & 17-3-2019 & 18-3-2019 & 20-3-2019 & 21-3-2019 \\
\hline 5 & 24-3-2019 & 25-3-2019 & 27-3-2019 & 28-3-2019 \\
\hline 6 & 31-3-2019 & 1-4-2019 & 3-4-2019 & 4-4-2019 \\
\hline 7 & 7-4-2019 & 8-4-2019 & 10-4-2019 & 11-4-2019 \\
\hline 8 & 14-4-2019 & 15-4-2019 & 17-4-2019 & 18-4-2019 \\
\hline \multicolumn{3}{|c|}{ Post-measurement } & \multicolumn{2}{|c|}{ Sunday 21-4-2019 } \\
\hline
\end{tabular}

Statistical Treatment:

The researcher used SPSS Software to calculate: Mean - SD Median - Kurtosis - Squewness - Correlation Coefficient (R)-Cronbach's Alpha - (t) test - improvement percentage.

Results:

Table (9): Difference Significance Between Pre- and PostMeasurements of Participants on the Separation Anxiety Scale $(\mathbf{n}=36)$

\begin{tabular}{|c|c|c|c|c|c|c|c|c|c|}
\hline & \multirow{2}{*}{ Measurement } & \multicolumn{2}{|c|}{ Pre- } & \multicolumn{2}{|c|}{ Post- } & \multirow{2}{*}{$\begin{array}{c}\text { Means } \\
\text { differences }\end{array}$} & \multirow{2}{*}{$\begin{array}{c}\text { Standard } \\
\text { error }\end{array}$} & \multirow{2}{*}{ (T) } & \multirow{2}{*}{$\begin{array}{c}\text { Improvement } \\
\text { percentage } \\
(\%)\end{array}$} \\
\hline & & Mean & SD \pm & Mean & $\mathrm{SD} \pm$ & & & & \\
\hline \multirow{5}{*}{ 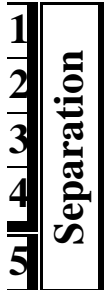 } & Personal & 34.916 & 1.556 & 14.583 & 0.500 & 20.333 & 0.251 & 80.695 & $\overline{58.234}$ \\
\hline & Social & 22.027 & 1.133 & 9.555 & 0.652 & 12.472 & 0.285 & 43.628 & 56.621 \\
\hline & Physiologica & 24.194 & 1.237 & 10.805 & 0.467 & 13.388 & 0.268 & 49.943 & 55.336 \\
\hline & Academic & 32.361 & 1.396 & 14.00 & 0.585 & 18.361 & 0.261 & 70.156 & 56.738 \\
\hline & Total & 113.50 & 2.813 & 48.944 & 0.984 & 64.555 & 0.548 & 117.723 & 56.876 \\
\hline
\end{tabular}

(t) table value on $P \leq 0.05=2.021$

Table (9) showed statistically significant differences between the pre- and post-measurements of participants on decreasing separation anxiety in favor of post-measurements. 


\section{Discussion:}

Table (9) indicated statistic significant differences between the preand post-measurements of participants on decreasing separation anxiety in favor of post-measurements as (t) calculated values were (80.695), (43.628), (49.943), (70.156) and (117.723) for personal, social, physiological and academic dimensions and the total score of the separation anxiety scale respectively. These values are all higher than $(\mathrm{t})$ table value).

Table (9) also indicated that improvement percentages were (58.234\%), (56.621\%), (55.336), (56.738\%) and (56.876\%) for personal, social, physiological and academic dimensions and the total score of the separation anxiety scale respectively.

The researcher thinks that this decrease in separation anxiety among children is due to the sports recreational program that included activities and games that work on improving interaction with others, forming relations, cooperation, sharing, courage, self-confidence and comfort in addition to decreasing fears and sense of danger and overcoming difficulties. This decreases separation anxiety and improves the children's abilities to face the separation situations, overcome them and live normally. The program had positive effects either when applied at school or at home as negative responses like continuous crying and inability to interact with peers during school activities decreased significantly.

These results are consistent with several previous studies. Allam, M. (2011) (5) indicated that the recreational programs had positive effects on improving the sense of security and comfort and decreasing fears, anxiety and sadness among children. Rabia, F. (2012) (13) indicated that the artistic activities program had positive effects on decreasing separation anxiety manifestations among children. SHoaakazemi et al. (2012) (16) indicated that the group=play intervention had significant effects on decreasing separation anxiety among children. Khadar et al. (2013) (9) indicated that the artistic intervention based on drawing therapy had positive effects on decreasing the intensity of separation anxiety symptoms in children. AlGanaee, M. (2014) (4) indicated that the family guidance intervention had positive effects on decreasing separation anxiety in children. Bilwani \& Gupta (2015) (7) indicated that the behavioral modification intervention had positive effects on decreasing separation anxiety among children. Abbasi et al. (2016) (1) indicated that the behavioral cognitive intervention had positive effects on decreasing separation anxiety among children. Zebdi \& Lignier (2017) (21) indicated that the behavioral cognitive intervention had positive effects on improving children's behaviors including social participation, school participation and separation anxiety. Abd Al-Fattah, S. (2018) (2) indicated that behavioral cognitive intervention had positive effects on decreasing separation anxiety among children. 
Recreational games and activities improve quality of life through improving happiness and comfort among participants. It improves physical, mental, social and psychological well-being in addition to the achievement motivation, forming friendships, cooperation, interaction with others, self-assertiveness, comfort and self-confidence. It protects individuals from fear, anxiety, depression stress and psychological distress (18: 17-26) (10: 205-261) (20: 44-46) (19: 485-490) (14: 1-156).

The researcher thinks that the recreational games' Program decreased separation anxiety among children as recreational games and activities are of major importance for integrated child growth in all aspects including physical, mental, social and physiological aspects. They are required for daily life activities to enhance and improve individuals and societies. This proves the research hypothesis.

\section{Conclusion:}

According to this research aim, hypothesis, methods and results, the researcher concluded that the sports recreational program had positive effects on decreasing separation anxiety among children.

\section{Recommendations:} following:

According to this conclusion, the researcher recommends the

- Generalizing the application of the recommended recreational games' Program for all children in all schools and institutes.

- Helping children to identify themselves and form friendships in addition to improving their social skills and expressing their feelings freely and confidently and to use recreational games and activities in raising, educating and training them.

- Performing more studies to design specialized recreational Programs in physical, health, mental, social and psychological aspects of children to decrease and solve problems and achieve advance.

\section{References:}

1- Abbasi, Z., Amiri, S., \& Talebi, H. (2016) : The Effective Comparison Between Modular Cognitive Behavioral Therapy (MCBT) and Child-Parent Relationship Training (CPRT) in Children with Separation Anxiety Symptoms. The Social Sciences, 11(6), 890-902

2- Abd Al-Fattah, Sara G. (2018): Effectiveness of a behavioral cognitive intervention in decreasing separation anxiety among 
children. Master dissertation - Faculty of Education - Tanta University (in Arabic).

3- Abd Al-Moaty, Hassan Mostafa (2003): Psychological Disorders in Childhood and Adulthood (Causes - Diagnosis - Treatment). Dar Al-Kahira Press - Cairo - Egypt (in Arabic).

4- Al-Ganaei, Mona Badr (2014): Effectiveness of a family guidance intervention in decreasing separation anxiety among kindergarten children in Kuwait. Journal of Faculty of Education, No. 4, part II (56), PP: 389-464. Faculty of Education - Tanta University (in Arabic)

5- Allam, Maisa H. A. (2011): Effectiveness of a recreational activities' intervention in decreasing sadness among kindergarten children. PhD dissertation - Institute of Post-Graduate Studies in Childhood - Ain Shams University (in Arabic)

6- American Psychiatric Association. (2013) : DIAGNOSTIC AND STATISTICALMANUAL OF MENTAL DISORDERS, DSM5TM,Washington, DC, London, England

7- Bilwani, R., \& Gupta, M. (2015) : A model for management for young children aged 3-7 years with Separation Anxiety Disorder. Journal of Indian Association for Child \& Adolescent Mental Health, 11(1), p 32 - 55

8- Chorpita, B. F., Taylor, A. A., Francis, S. E., Moffitt, C., \& Austin, A. A. (2004) : Efficacy of modular cognitive behavior therapy for childhood anxiety disorders. Behavior Therapy, 35(2), 263-287

9- Khadar, M. G., Babapour, J., \& Sabourimoghaddam, H. (2013) : The effect of art therapy based on painting therapy in reducing symptoms of separation anxiety disorder (SAD) in elementary school boys. Procedia-Social and Behavioral Sciences, 84, 16971703

10- Lo, C. Y., Chang, H. I., \& Chang, Y. T. (2009) : Research on Recreational Sports Instruction Using an Expert System, $5^{\text {th }}$, International Conference, Active Media Technology, SpringerVerlag Berlin Heidelberg, P 250 - 262

11- Mohr C, Schneider S. (2013) : Anxiety disorders. Eur Child Adolesc Psychiatry 22(1):17-22

12- Owais, Mosaad (2008): Recreation and Leisure Time. Sayed Owais Association for Social Studies and Research - Giza - Egypt (in Arabic)

13- Rabia, Fatma S. A. (2012): Effectiveness of an artistic activities' intervention on decreasing some aspects of separation anxiety among KG-1 children. Journal of Faculty of Education, No. 12, Part II, PP: 715-733. Faculty of Education - Port Said University (in Arabic). 
14- Richard Kraus. (2015) : Recreation and leisure in modern society, 10th Edition, Jones and Bartlett Publishers, Canada

15- Schneider, S., Blatter-Meunier, J., Herren, C., Adornetto, C., InAlbon, T., \& Lavallee, K. (2011) : Disorder-specific cognitivebehavioral therapy for separation anxiety disorder in young children: a randomized waiting-list-controlled trial. Psychotherapy and psychosomatics, 80(4), 206-215

16- SHoaakazemi, M., Javid, M. M., Tazekand, F. E., Rad, Z. S., \& Gholami, N. (2012) : The effect of group play therapy on reduction of separation anxiety disorder in primitive school children. Procedia-Social and Behavioral Sciences, 69, 95-103

17- Silverman, W.K. \& Dick-Niederhauser, A. (2004) : Separation anxiety disorder. In T.L. Morris \& J.S. March (eds), Anxiety Disorders in Children and Adolescents. New York: Guilford Press

18- Taha, Taha A. (2006): Introduction to recreation. - Dar Al-Wafa Alexandria - Egypt (in Arabic).

19- Titze, S., Merom, D., Rissel, C., \& Bauman, A. (2014) : Epidemiology of cycling for exercise, recreation or sport in Australia and its contribution to health-enhancing physical activity, Journal of Science and Medicine in Sport, Vol. 17 (5), 485-

20- Tolba, Mahmoud I. (2010): Psychology of recreation and leisure time. Islamic Graphic - Cairo - Egypt (in Arabic).

21- Zebdi, R., \& Lignier, B. (2017) : Anxiété de séparation et refus scolaire anxieux chez l'enfant: étude de cas. Journal de Thérapie Comportementale et Cognitive, 27(4), 165-176. 